\title{
A ideia de Natureza no limiar da Modernidade: novos saberes e a quebra de paradigmas
}

DOSSIER RIOS E CidADES: ARAGUAIA

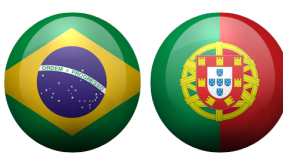

\section{Paulo de Assunção}

Professor da Universidade Mackenzie. Pós-Doutor (Universidade de Lisboa); Doutor em História Ibérica (École des Hautes Etudes en Sciences Sociales - Paris); Doutor em História Econômica e Social (Universidade Nova de Lisboa); Doutor em História Social (Universidade de São Paulo). Pesquisador do Centro de Literaturas e Culturas Lusófonas e Europeias (Universidade de Lisboa). São Paulo [SP] Brasil <assuncao@prestonet.com.br>.

\section{Resumo}

Este artigo tem como objetivo discutir as transformações ocorridas a partir do século XVI que influenciaram a leitura e compreensão da natureza. Para entender melhor esta questão, abordamos alguns aspectos do ambiente científico que se instaurou nesse período. Para tanto, optamos por empreender uma visita ao contexto da ciência e das sociedades científicas que conquistam importância a partir daquele momento. Procuramos apresentar alguns importantes aspectos do desenvolvimento da História Natural e o aparecimento das novas experiências. Desta forma, tivemos a pretensão de destacar a presença de uma comunidade científica que atuava em parte estimulada pelo movimento das descobertas marítimas.

\section{Palavras-chave}

Natureza. História. Ciência. Descobertas.

\section{The idea of Nature in the threshold of Modernity: new knowledge and the breaking of paradigms}

\begin{abstract}
This article aims to discuss the changes that have occurred since the sixteenth century that influenced the reading and understanding of nature. To better understand this issue, we discuss some aspects of the scientific environment, which arose during this period. We chose to undertake a visit to the context of science and scientific societies that gain significance from that moment. We present some important aspects of the development of Natural History and the emergence of new experiences. Thus, our claim was to highlight the presence of a scientific community that worked in part stimulated by the movement of maritime discoveries.
\end{abstract}

\section{Keywords}

Nature. History. Science. Discoveries. 
No final da Idade Média o pensamento cristão passava por uma série de questionamentos sobre a própria ordenação da Igreja e do poder temporal. Paulatinamente o homem lançava o olhar para as coisas do mundo natural, como uma curiosidade maior. Seu grande desafio era aprender a olhar o mundo que o cercava. 0 interesse pela natureza despontava no século XVI como algo irreversível. O Renascimento promoveu importantes transformações no século XV que marcariam o desígnio da humanidade. 0 debate de ideias fez surgir em Florença a Academia Platônica, com figuras de humanistas como Marsílio Ficino (1433-1499), Pico della Mirandola (1463-1494), dentre outros. Rapidamente novas academias são fundadas pela Europa, assumindo nuances específicas em cada região. Concomitantemente, despontam novos seguidores de Aristóteles, como Pietro Pomponazzi (1462-1525), observando que certos tipos de eventos, que pareciam milagrosos, eram de fato fenômenos de ordem natural. Suas ideias contra as proposições da Igreja o tornaram alvo de perseguições e suas obras proibidas pelo Concílio de Trento (1545-1563) ${ }^{1}$. Uma ebulição de pensamentos dinamizava a sociedade renascentista apesar de uma forte corrente conservadora (Marías, 2004).

Neste momento, é possível identificar que entre o século XV e XVI emergem novas discussões sobre a ideia de natureza. Os pensadores dialogaram com as ideias do período medieval e da antiguidade clássica e contribuíram com novos elementos na leitura dos fenômenos do mundo natural. O Humanismo, como movimento literário e filosófico que nasce nas cidades italianas na segunda metade do século XIV, conquistou rapidamente a Europa, celebrando o ser humano. As ideias humanistas se contrapunham à visão medieval, em que o papel do homem estava sujeito aos perigos do mundo, normalmente oscilando do pecado à salvação. Neste sentido, era preciso pensar o papel do homem num novo universo. Para o Humanismo, o tema central era a questão da liberdade do homem e a sua capacidade de criar um novo projeto de vida. Como centro de tudo, deveria engajar-se na busca da verdade. 0 ser humano possuía capacidade intelectual ilimitada para construir o saber; bastava usar suas faculdades mentais. Os pensadores humanistas entendiam que havia muita ignorância na sociedade, sendo o indivíduo sufocado pela religião. 0 homem devidamente instruído poderia chegar à liberdade em sua plenitude (Hale, 1983).

O olhar para a Antiguidade serviu para recuperar textos antigos, mas também para discutir a formação do homem. A educação do período não o preparava para exercer o seu papel na sociedade, conforme sua capacidade. 0 homem necessitava de uma educação adequada à perspectiva histórica, cheia de contrastes que exigiam solução.

A obra de Erasmo de Rotterdam (1466-1536), Elogio da Loucura (1509), criticava a sociedade e os seus valores. Momento em que a riqueza dos príncipes contrastava com a pobreza da população, da mesma forma que o desregramento de papas e bispos revelava a fragilidade do cristianismo. Haveria justiça na sociedade? Onde ela estaria? 0 ser humano estava insatisfeito e Erasmo de Rotterdam procurou, por meio do seu escrito, questionar a sanidade do mundo. 0 "príncipe dos humanistas" entendia que a razão humana era capaz de distinguir entre o bem e o mal, sendo o homem capaz de definir o seu destino. 0 texto instigava os leitores à reflexão e a entenderem que não se estava tocando [...]

[...] na oculta cloaca de vícios da humanidade, nem revelamos as suas torpezas e infâmias, limitando-nos a mostrar o que nos pareceu ridículo. Se, apesar de tudo, ainda houver ranzinzas e descontentes, que ao menos observem como é bonito e vantajoso ser acusado de loucura (Rotterdam, 1988, p. 6).

A sociedade renascentista era algo digno de se questionar. Para Erasmo, a maioria dos homens era ingrata, fingida e alimentava comportamentos errados. Os sábios se perdiam em divinizar suas ideias, tornando-se pessoas desagradáveis e de difícil convívio. Além disso, alimentavam um desprezo pelos demais e não gostavam absolutamente de ninguém. Para ele, nesse universo:

\footnotetext{
${ }^{1}$ O Concílio de Trento ocorreu em três sessões diferentes: a primeira entre 1545 e 1549, a segunda entre 1551 e 1552 e a terceira entre 1562 e 1563. Foi o concílio de maior duração da Igreja e teve como objetivo principal especificar as doutrinas católicas, os sacramentos e os cânones bíblicos.
} 
Quase todos os homens são loucos; mas por que quase todos? Não há quem não faça suas loucuras e, a esse respeito, por conseguinte, todos se assemelham; ora, a semelhança é justamente o principal fundamento de toda estreita amizade (Rotterdam, 1988, p. 29).

Os Humanistas procuraram repensar os filósofos antigos a fim de integrá-los na concepção cristã de vida, nesse novo universo da loucura. Contudo, o horizonte cristão se ampliara progressivamente. 0 homem avançava pelo Oceano Atlântico e encontrava regiões desconhecidas. As certezas eram postas à prova. 0 mundo passava a ser uma grande indagação. Como registrou Thomas More (1478-1535), na sua obra Utopia, o avanço em direção ao Equador gerava questionamentos expressos na fala do personagem Hitlodeu:

[...] de uma parte e de outra, no espaço compreendido pela órbita do sol, não viram senão vastas solidões eternamente devoradas por um céu de fogo. Aí, tudo os aturdia de horror e espanto. A terra inculta tinha apenas como habitantes os animais mais ferozes, os répteis mais terríveis, ou homens mais selvagens que os animais. Afastando-se do equador, a natureza se abrandava pouco a pouco; o calor é menos abrasador, a terra se cobre de uma ridente verdura e os animais são menos selvagens. Mais longe ainda, aparecem povos, cidades, povoações, em que se faz um comércio ativo por terra e por mar, não somente no interior e com as fronteiras, mas entre nações muito distantes (More, 1985, p. 168).

0 registro de um mundo imaginário, próximo ao ideal, é delineado por Thomas More. Nesse universo utópico, os meios de produção pertenciam a todos e a atividade comercial beneficiava o coletivo. A liberdade religiosa reinava e o humano era instado a viver conforme a sua natureza. Este novo modelo de governo e sociedade demoraria a chegar, apesar de ser desejado por muitos. Contudo, uma questão se fazia pertinente: Esta utopia seria possível?

A partir do Renascimento, o espaço começou a ser construído sobre novos moldes. A geometria permitiu imaginar outras representações espaciais. Estas, antes de serem uma imitação do real, eram uma ilusão. Havia uma representação espacial simplificada que atendia à uma forma de perceber o espaço (Heller, 1982). 0 movimento humano pelos mares modificou estas representações e o ser humano foi convidado a imaginar e a questionar como fez Hitlodeu. Todavia, a racionalidade dos interesses econômicos nem sempre explicou o gosto pela aventura, pelo desconhecido ou novo, que só a mentalidade medieval tinha alimentado. As descobertas, ao sintetizarem um conjunto de novos processos técnicos (teóricos e empíricos), astronômicos, em nível da arte náutica possibilitaram a abertura dos olhos do mundo (Martin, 1996).

Portugal assumiu papel de destaque nesta empreitada, além de promover uma verdadeira revolução nas artes náuticas; impulsionou o conhecimento sobre as novas terras americanas. 0 mundo passou a ser cada vez mais representado, os espaços planetários construídos na sua aproximação com a realidade, seguindo os reconhecimentos que cada viagem exploratória promovia, enquanto as configurações fantasiosas iam perdendo sua intensidade (Barreto, 1986). 0 contorno do mundo começava a ser mais definido. $O$ homem europeu conseguia realizar uma representação abstrato-conceitual nos mapas que ganhavam difusão nesse momento, questão posta desde a Antiguidade pelos pensadores pré-socráticos. Como afirma Guillermo Giucci "a única fonte verdadeira e confiável de conhecimento do Novo Mundo apóia-se na experiência pessoal. E a experiência do desconhecido e ameaçador implica uma reavaliação profunda da série de conceituações imaginárias erigidas a partir da ilusão" (Giucci, 1992, p. 26).

O homem ia conseguindo ver a Terra dissociada da imagem Céu-Inferno, enquanto esferas interligadas e decorrentes. A imaginação humana estava simbolicamente livre para romper os estreitos limites da Terra e dominá-lo; tal como os primeiros seres humanos do período paleolítico, que desenhavam nas cavernas, o homem, ao delinear os contornos do mundo, tornava-se possuidor da coisa representada. 0 desejo humano de captura do mundo natural era uma constante.

Os descobrimentos, ao revelarem para a humanidade a dimensão do globo terrestre, desencadeiam uma nova reordenação de estruturas de pensamento, uma mudança histórica até então nunca vista. Segundo Edmundo O’Gorman, o descobrimento da América: 
[...] não deixou de refletir nas novas ideias astronômicas que deslocaram a Terra da sua condição de centro do universo para convertê-la num carro alado de observação do céu, foi uma mudança cujas conseqüências ultrapassaram o seu aspecto meramente físico. É claro que se o mundo perdeu sua antiga natureza de cárcere para converter-se em casa aberta e própria, é porque o homem, por sua vez, deixou de imaginar-se a si próprio como um servo prisioneiro para transfigurar-se em dono e senhor do seu destino. Em vez de viver como um ente predeterminado num mundo inalterável, começou a se imaginar como dotado de um ser aberto, habitante de um mundo construído por ele à sua medida e semelhança (O'Gorman, 1992, p. 185).

O palco da atuação humana era ampliado, assim como o seu conhecer, e essa "novidademudança" é responsável "por um novo mundo de coisas, informações, dados, diferenças etc.". (Barreto, 1987, p. 41) As descobertas prepararam o caminho para uma nova ciência, o homem despertava para sua consciência crítica, desterrando do saber os erros longamente enraizados no pensamento europeu (Carvalho, 1947, p. 12).

As descobertas marítimas, ao permitirem um "re-conhecimento" do mundo, traziam consigo uma nova leitura da existência humana. A Igreja, detentora do saber primordial sobre as origens da civilização ocidental, revê as suas afirmações. 0 microcosmo medieval é implodido, e surge um macrocosmo que o pensamento ocidental tem que reordenar.

O novo precisava ser inserido no discurso religioso das Escrituras Sagradas, como parte componente dissociada da célula materna. As terras americanas acenavam para um reencontro das partes, até então desunidas, a ideia de um jardim de delícia mostrava-se presente. Uma única lógica as envolvia, pois uma única razão as tinha tornado possível. 0 ponto comum era que o monoteísmo cristão reunia de maneira convergente todas as coisas criadas pelo ente divino (Heinberg, 1991).

A verdade católica atingia uma amplitude máxima, tendo como certeza que Deus ofertara aos homens europeus a possibilidade de conhecer os seus pares, regulados por uma mesma ordem e uma mesma regra que era o cristianismo. Deus oferecera, senão o Paraíso, pelo menos algo muito próximo de uma situação idílica, há muito tempo desejada. As novas terras foram inseridas num contexto religioso de concepção que entendia que o universo, feito por Deus, era ampliado pelo engenho do homem europeu.

As descobertas eram o sinal de uma nova era. $\mathrm{O}$ homem conseguia contemplar a onipotência divina e sua criação na sua plenitude. As novas tecnologias da navegação possibilitaram o alargamento do horizonte da cristandade. Se a fé católica se espalhava pelo mundo, o movimento do pensamento científico ia assumindo contornos mais nítidos. 0 conhecimento sobre os mares acumulados por séculos passou a ser cada vez mais sistematizado, conduzindo ao que seria conhecido como revolução científica. Como salienta Paolo Rossi:

A propósito do nascimento da ciência moderna se falou e ainda se fala, justamente, de 'revolução científica'. Um dos aspectos característicos das revoluções consiste no fato de que elas não só olham para o futuro, dando vida a algo que antes não existia, mas também constroem um passado imaginário que, em geral, tem características negativas (Rossi, 2001, p. 14).

Portugal fez parte desse processo de transformação, olhando para o futuro e contribuindo para realizar as transformações da sociedade no caminho de um novo pensamento. D. Henrique, o navegador (1394-1460), foi o agente da reunião de especialistas na vila de Sagres. Para lá afluíram matemáticos, cosmógrafos, cartógrafos e especialistas da construção naval do período. 0 resultado deste empenho foi o avanço marítimo português vencendo o Cabo Bojador, aventura feita por Gil Eanes (século XV) em 1434. Aos poucos, os mapas foram sendo modificados a partir das informações dos viajantes. $\mathrm{O}$ Infante D. Henrique pautou-se pela famosa máxima de Gneu Pompeu Magno (106 a. C. - 48 a. C.), navigare necesse est, vivere non est necesse. Portugal neste momento assumiu um papel importante no movimento de viagens marítimas que levaram ao reconhecimento das ilhas do Atlântico e de partes da África, para em seguida chegar à Índia e à América. 
Em 1472, Abraham Zacuto (c.1450-1510) estabeleceu o Almanach Perpetuum (1473-1478), compôs tabelas da declinação do sol e aperfeiçoou o astrolábio que seriam utilizadas como referência nas viagens posteriores, como a de Vasco da Gama (ca. 1460-1524) e de Pedro Álvares Cabral (c.1467-1520). No decorrer do século XVI, as viagens marítimas permitiram que novos instrumentos e tábuas de medição fossem criados ou melhorados. Da mesma maneira, manuais de navegação, com descrições geográficas aparecem como a Suma de Geographia, do navegador espanhol Martín Fernandez de Enciso (1470-1528), publicado em 1519. Os registros sobre viagens ganharam uma ampla difusão e rapidamente se evidencia a importância da circulação da informação e das trocas culturais e econômicas que se empreenderam, onde as descrições sobre a natureza aparecem com mais constância. Os europeus olhavam atentos para as terras distantes, buscando encontrar algo possível de ser explorado e que gerasse riqueza.

O homem observava, analisava e construía novas leituras sobre o mundo natural e a dinâmica que envolvia a Terra. Em 1537, Pedro Nunes (1502-1578) publicava o Tratado da Sphera de Johannes Sacrobosco (c.1195 - c.1256), explicando como determinar a latitude a partir da medição de duas alturas do Sol. A invenção do quadrante náutico ${ }^{2}$, do noturlábio ${ }^{3}$, o octante ${ }^{4}$, bem como outros instrumentos e tábuas astronômicas permitiram o rápido desenvolvimento da navegação e a precisão do navegar, que seriam fundamentais para os séculos seguintes. 0 desconhecimento de tais técnicas impedia a localização de embarcações, tendo em vista as correntezas do mar e os efeitos do vento. Desta forma, a experiência e o conhecimento eram fundamentais para o êxito das expedições. Pedro Nunes defendia que o conhecimento científico deveria ser compartilhado para resolver problemas práticos da navegação valendo-se de cálculos matemáticos (Dias, 1988).

A obra Arte de Navegar de Pedro de Medina (1493-1567) foi editada em Valadolid, no ano de 1545. Nos anos seguintes a obra foi traduzida para outras línguas e ganhou novas edições. 0 sucesso desse trabalho consistia na forma de sua narrativa; de fácil compreensão e de interesse para os navegantes, fornecia informações sobre os movimentos do mar ou dos ventos e a relação com as fases da lua, como fazer uso da altura do sol, dentre outros assuntos náuticos (Hutter, 2004).

Observa-se que as grandes viagens marítimas incorporaram novos conhecimentos que foram sendo encontrados na África, Ásia e América. Isto estimulou a realização de representações, segundo os reconhecimentos que cada viagem exploratória promovia, fazendo que as imagens fantasiosas fossem perdendo sua intensidade. As formas de pensar a realidade sofriam transformações, migrando da fé para a racionalidade. 0 empirismo sensorial, atribuindo papel central à vivência de cada indivíduo pela evidência da observação, entendia que da própria vivência derivava da acumulação informativa que compunha o arcabouço de conhecimento do indivíduo.

A cartografia náutica, que paulatinamente floresceu em qualidade e quantidade, consolidou uma consciência geográfica global. As explorações feitas pelos navegadores lusitanos, dentre eles: Diogo Cão (século XV), Bartolomeu Dias (1450-1500), Vasco da Gama e Pedro Álvares Cabral, entre outros, além de inaugurarem o contato com as novas civilizações da África, da Índia e da América, possibilitaram a união dos mares até então desconhecida, rompendo com as concepções medievais influenciadas pela Bíblia e pelos textos clássicos da Antiguidade.

Uma nova visão do mundo, mais próxima da realidade e, por conseguinte, mais detalhada, superava os esboços cartográficos antigos. 0 homem dava contorno ao seu mundo, apreendendo-o e tornando-o objeto de estudo. Os descobrimentos, ao revelarem a verdadeira dimensão do globo

\footnotetext{
2 Instrumento utilizado para a medição da distância zenital, criado por John Davis em 1590. A medição angular feita pelos sextantes e quadrantes e o conhecimento da geometria favoreceram novas formas de representação. A utilização do quadriculado nas construções geométricas do espaço, principalmente na cartografia, contribuíram para calcular com mais precisão um local no mapa. O Renascimento ao desenvolver e sistematizar a perspectiva plana permitiu a representação tridimensional num plano, contribuindo para o avanço técnico do período seguinte.
}

${ }^{3}$ Instrumento que permitia corrigir de forma apropriada a altura da estrela Polar para obter a latitude.

${ }^{4}$ Instrumento que mede ângulos até $1 / 4$ da circunferência, ou $90^{\circ}$. 
terrestre para a humanidade, desencadeiam um novo reordenamento das estruturas de pensamento, uma mudança histórica até então nunca vista. 0 palco da atuação humana era ampliado, assim como o seu conhecer. As descobertas prepararam o caminho para uma nova ciência, na medida em que a natureza passava a ser indagada pelo homem. As certezas eram relativas. Havia dúvidas e buscavam-se respostas (Azzi, 1983).

A partir da Idade Média, a ideia da esfericidade da Terra já estava consolidada. Contudo, a discussão convergiu para outro aspecto: seria o Sol ou a Terra o centro do Universo. Os antigos acreditavam que a Terra era estacionária e que todos os corpos celestes se moviam no seu entorno, em órbitas circulares. A invasão muçulmana na Península Ibérica permitiu o estabelecimento de escolas de Astronomia, compilando dados para a tábua astronômica Hakémite. Nos séculos XIII e XIV, entre os astrônomos, já circulava a ideia da teoria heliocêntrica que não era aceita pela Igreja.

Nicolau Copérnico (1473-1543), ao defender a ideia de que o Sol estava em repouso e que os demais planetas giravam no seu entorno, lançou a base da nova astronomia, mudando o referencial de leitura consagrado desde a Antiguidade. 0 estudioso defendia que o movimento dos astros dependia das distâncias dos planetas em relação ao sol, tese que não foi aceita pela Igreja. Em 1543, Nicolau Copérnico publicou a obra De Revolutionibus Orbium Coelestium (Da Revolução de esferas celestes), na qual afirmava que não havia um único centro para todos os corpos celestes ou esferas, como afirmara Cláudio Ptlomoeu (90-168). Copérnico entendia que existiam dois centros de rotação, sendo a Terra o centro da rotação da Lua e o Sol era o centro da rotação de outros planetas; por conseguinte, o sol era excêntrico em relação ao centro do universo. 0 estudioso afirmava que o centro da terra não coincidia com o centro do universo, mas apenas com o centro da gravidade e da esfera da lua, apresentando um novo problema que era a explicação sobre a gravidade. Copérnico defendia que a relação entre a distância Terra-Sol e a altura do firmamento era menor do que a relação entre o raio terrestre e a distância. (Khun, 1990). Afirmava ainda que todos os movimentos que apareciam no firmamento não eram derivados de movimentos do firmamento, mas sim do movimento da Terra. 0 firmamento mantinha-se imóvel, enquanto a Terra realizava uma completa rotação sobre os seus polos fixo em movimento diuturno. Da mesma forma, chamava a atenção para o fato de que aquilo que parecia movimentos do Sol não derivava deles, mas do movimento da Terra ao redor do Sol, o que implicava afirmar que a Terra possuía mais de um movimento. Copérnico acreditava que o movimento da Terra era suficiente para explicar as desigualdades que apareciam no céu. Como bem lembra Paolo Rossi:

A simplicidade do novo sistema, no entanto, era mais aparente do que real: para justificar os dados das observações, Copérnico foi forçado, em primeiro lugar, a não fazer coincidir o centro do universo com o Sol (o seu sistema foi chamado de heliostático, ao invés de heliocêntrico), mas com o ponto central da órbita terrestre; em segundo lugar, foi obrigado a introduzir de novo, como em Ptolomeu, uma série de círculos girando em torno de outros círculos; e finalmente atribuir à Terra (além do movimento de rotação ao redor do seu eixo e de translação ao redor do Sol) um terceiro movimento de declinação (declinationis motus) para justificar a 'invariabilidade do eixo terrestre com relação à esfera das estrelas fixas (Rossi, 2001, p. 120).

As ideias defendidas por Nicolau Copérnico levavam o homem a abandonar as crenças antigas para construir uma nova astronomia, levantando novas discussões quanto às recentes e revolucionárias proposições.

O conhecimento da natureza podia ser atingido pela experiência direta, dando destaque também para a intuição e a emoção. A lógica e a ideia de uma ordem racional da natureza, defendida pela escolástica, passou por questionamentos e provocou novas especulações. 0 pensamento moderno palmilhava com cuidado este universo, demonstrando uma falta de consciência sobre as transformações que estavam sendo engendradas e os paradigmas entravam em crise.

Este processo de reordenamento intelectual contou com vários protagonistas que contribuíram, cada um, com novos conhecimentos que afetariam o conjunto de saberes sobre o mundo natural. Um desses protagonistas foi Bernardino Telésio (1509-1588) que escreveu a obra De rerum 
natura iuxta propria principia (A nova natureza se ajusta aos próprios princípios), na qual explica a natureza a partir dos princípios universais imanentes à mesma natureza. 0 mundo natural era constituído de matéria, considerada homogênea e inerte, e de força que animava e transformava continuamente toda a matéria. Alertava para o fato de que muitos tinham investigado a natureza com grandes fadigas e "inutilmente". Indagava: 0 que a natureza poderia ter revelado? 0 ser humano ao buscar o entendimento da natureza esqueceu que era importante estudar cada uma das partes, a exemplo do estudo de Telésio, seguindo os "sentidos e a natureza nada mais; aquela natureza que, concordando sempre consigo própria, age e efectua sempre as mesmas coisas e do mesmo modo" (Einaudi, 1990, p. 23).

Outro expoente foi Giordano Bruno (1548-1600) que nasceu em Nola, entrando ainda jovem na Ordem dos Dominicanos. Foi acusado de heresia e afastado de sua ordem, sendo posteriormente processado pelo tribunal da Inquisição e condenado à morte. As obras principais de Giordando Bruno que geraram polêmica e causaram a sua acusação foram: De la causa principio e uno (1584); De l'infinito, universo e mondi (1584); De gli Eroici furori (1585); De innumerabilibus, immenso et infigurabili (1591). Para Giordoano Bruno, o conhecimento se dividia em quatro graus em ordem hierárquica ascendente. Primeiro, eram os "sentidos", cujo objeto era o sensível, entendo que a verdade que manifestava era mera aparência. A "razão" vinha em seguida, e por ela é que se atingia a verdade num processo dialético, discursivo, sucessivo. 0 terceiro grau era o "intelecto", condutor imediato para a verdade. E no último grau a "mente", que atingia a verdade na sua unidade e numa simplicidade absoluta (Bruno, 1984).

A Igreja, ao buscar unidade e hegemonia sobre a sociedade, não admitia que se proliferassem ideias divergentes daquelas que os teólogos propunham. Se os mecanismos de perseguição e controle se ampliavam, estes não conseguiram inibir o desejo humano de questionamento. A epopeia da ousadia em saber e conhecer estava apenas começando e colocava em dúvida as ideias defendidas pela Igreja.

Galileu Galilei (1564-1642), no livro Discorsi e Dimostrazioni Matematiche Intorno a Due Nuove Scienze (Discurso e demonstrações matemáticas sobre as duas novas ciências - 1638), registra a importância das observações e informações que tivera do Arsenal de Veneza, local onde se fabricavam navios e armas, considerado como um local de produção de conhecimento (Braga et al., 2005, p.37). Seu estudo atacava o Universo fechado e hierarquizado da física escolástica, propondo uma ideia de espaço a partir da geometria. Além disso, rompia com a concepção aristotélica de repouso, defendendo a ideia de movimento. Proposições que alteravam os conceitos vigentes (Freitas, 2005).

O astrônomo Johannes Kepler (1571-1630), ao tomar o sol como ponto comum às órbitas planetárias, esboçou a possibilidade de uma dinâmica no sistema heliocêntrico, que poderia explicar a queda dos corpos. Valendo-se dos trabalhos de seus antecessores, dentre eles Tycho Brahe (1546-1601), chegou a estabelecer duas leis que contradiziam em parte os estudos anteriores. A primeira era que os planetas descreviam um movimento elíptico no entorno do Sol, sendo que este ocupava um dos focos da elipse. A segunda era que as velocidades dos planetas eram variáveis ao longo da órbita, passando a ser mais veloz quando estavam próximas do sol. (Braga et al., 2005).

Os estudos do astrônomo alemão trouxeram grande impacto para os navegadores da época, pois ao analisar as tabelas astronômicas, identificou-se a necessidade de correções. 0 estudioso, ao estabelecer os princípios astronômicos da Lei das Áreas Iguais, a Lei das Órbitas Elípticas e a Lei da Proporcionalidade dos Quadrados das Revoluções e dos Cubos das Distâncias, permitiu que estes conhecimentos fossem incorporados aos dados astronômicos da navegação. Neste sentido, o movimento de descobertas da mesma maneira que gerou conhecimentos novos, incorporou diferentes conhecimentos aprimorados numa velocidade muito rápida (Rossi, 2001).

O alvorecer da modernidade despontou na Europa um conjunto de saberes teóricos e práticos construídos por diversas mãos. 0 trabalho de navegadores, cartógrafos, astrônomos, matemáticos abria campo para as investigações e especulações. Exigiu novos equipamentos e a mudança de referencial. 0 estudo da estrela Polar que permanecia fixa no céu, pois o eixo de rotação da Terra apontava para a direção da estrela, permitiu aos navegadores utilizá-la como referência durante a 
noite. Desta maneira, o termo "orientar", que era utilizado nas viagens terrestres por causa da tradição de se tomar Jerusalém como referência, cede espaço para o termo "nortear", fruto das observações astronômicas (Braga et al., 2005, p. 26).

Este conhecimento não foi construído apenas pelo Ocidente. 0 contato com o Oriente permitiu que os navegadores tivessem contato com outros povos, mas principalmente com outros conhecimentos sobre a arte de marear. Este intercâmbio representou uma ampliação das técnicas e por vezes uma melhoria qualitativa nas viagens marítimas. 0 olhar europeu se abriu para novos horizontes, percebendo a diversidade biológica. Ficava patente que só a experiência possibilitava conhecer o novo e rever o conhecimento legado pela Antiguidade.

O século XVI lançou um novo olhar para a natureza e para o corpo humano. Em algumas cidades italianas as investigações sobre o corpo humano foram intensificadas na medida em que textos árabes e gregos, traduzidos para o latim, conseguiram difusão. Na Universidade de Pádua (1222) o estudo da filosofia natural, além do conhecimento da obra aristotélica, e dos escritos de Cláudio Galeno (c.131-c.200) incorporou as ponderações de pensadores muçulmanos, como Averróis (1126-1198) (Braga et al., 2005, p. 26). 0 estudo do corpo humano, por meio de dissecações, foi importante para questionar o conhecimento vindo da Antiguidade. Andreas Vesalius (1514-1564) ao observar as dissecações procurou, com o auxílio de desenhista, fazer representações claras sobre as partes do organismo (ossos, músculos, sistema circulatório, sistema nervoso, abdômen, coração, pulmões, cérebro) influenciando os estudos sobre a anatomia humana (Rossi, 2001, p. 96). O médico William Harvey (1578-1657) concentrou os seus estudos no entendimento da circulação sanguínea. Empreendendo uma série de dissecações de animais diferentes, notou que o coração endurecia ao contrair-se, indício de que ele era um músculo. Outro aspecto observado era que as válvulas existentes só permitiam o fluxo de sangue num único sentido ${ }^{5}$. Para Harvey, o coração bombeava o sangue por artérias e veias, que compunham um único sistema de circulação.

A medicina avançava em descobertas sobre as partes que compunham o microcosmo humano. Os estudos dos órgãos e sua contribuição para o bom funcionamento do organismo revelavam uma complexa leitura do corpo humano, que funcionava a partir de sistemas. 0 próprio ser humano fazia parte de um sistema maior, que o unia ao mundo natural, do qual dependia. As interdependências provocavam discussão sobre os mecanismos da natureza e as contribuições que esta poderia trazer para a saúde do homem. Desta forma, é conveniente ressaltar que o saber sobre o organismo humano englobava o estudo da natureza, tendo em vista muitos médicos passavam a estudar as propriedades de substâncias advindas de plantas e animais que poderiam ser objeto de uso farmacêutico. E cada vez mais ele se apresentava ao homem, pois como afirmava Heráclito a natureza amava esconder-se (Khun, 2006).

Estudos começavam a ser publicados, procurando dar uma visão geral sobre o conhecimento do mundo natural. Girolamo Cardano (1501-1576), matemático e estudioso da mecânica e das obras dos gregos, escreveu duas obras De rerum varietate (1557) e De subtilitate (1550), visando à compreensão sobre a diversidade do mundo natural. Este pensador utiliza o recurso da analogia, como elemento do raciocínio, buscando construir a unidade das coisas (Crafton, 1999).

A crítica às concepções abstratas da natureza, que não conduziam à apreensão imediata, estava presente na reflexão de muitos pensadores. 0 Renascimento e o Humanismo determinaram que era preciso conhecer e não apenas ver. Desta forma, havia uma tendência para os pensadores defenderem que o verdadeiro conhecimento vinha da natureza, porque ela revelava a si própria, cabendo ao homem estabelecer os critérios de observação, a fim de obter as respostas (Khun, 2003).

Neste cenário, os estudos de botânica e zoologia ganharam estudos mais elaborados que influenciariam a caminhada das ciências nos séculos posteriores. Dentre os precursores estão Otto Brunfels (1488-1534), Jerome Bock (1498-1554) e Leonhart Fuchs (1501-1566) que realizaram trabalhos inovadores e passaram a ser considerados como os "pais alemães da botânica".

Otto Brunfels nasceu em Mainz, estudou no mosteiro de Estrasburgo. Naquele momento, as ideias

\footnotetext{
${ }^{5} \mathrm{O}$ que vigorava até aquele momento eram os estudos de Galeno que afirmava que o sangue era produzido no fígado a partir dos alimentos e que o sistema sanguíneo estava dividido.
} 
protestantes fervilhavam e Brunfels reorientou sua fé para o luteranismo. Atuou como professor e demonstrou possuir interesse pela medicina, sistematizando informações sobre a flora, e elaborou uma obra designada de Herbarum vivae eicones (Ilustrações vivas de plantas), publicado o primeiro volume em 1530 e o segundo no ano seguinte. (Ronan, 1987, vol. III, p. 18) A obra valiase das informações de Dioscórides (90-40 a.C. $)^{6}$ e de outros estudiosos de plantas; sua contribuição foi o registro de mais de duzentas plantas desenhadas por Hans Weiditz (1500-1536). As gravuras, de tamanhos variados, mostravam uma precisão científica que impressionava pela beleza, bem como pelos detalhes e por registrar o habitat natural da espécie. 0 olhar atento registra uma natureza em sua plenitude e pode ser considerado um marco no estudo da botânica no mundo ocidental.

Jerome Bock (1498-1554) também foi educado num meio católico, vindo posteriormente a abraçar o luteranismo. Pelas referências apresentadas no seu trabalho, ele provavelmente recebeu formação na área de medicina, especializando-se em botânica. Em 1539, publicou a obra o Neu Kreütter Buch (Novo livro das plantas), com descrições de plantas, adotando critérios mais objetivos para o detalhamento da espécie; realizou um histórico de cada uma e as possíveis interligações entre elas, valendo-se de referências de Brunfels e David Kandel (1520-1592) (Ronan, 1987, vol. III, p. 19).

Leonhart Fuchs (1501-1566) era luterano e também teve formação em Medicina. Em seus trabalhos a influência dos escritos gregos é marcante, principalmente de Pedânio Dioscórides (ca. 40-90) e Galeno, demonstrando um distanciamento respeitoso em relação às fontes medievais. Sua obra sobre ervas medicinais, De historia stirpium (A história natural das plantas - 1542) foi ricamente ilustrada com desenhos de Heinrich Füllmaurer (séc. XVI) e Albrecht Meyer (séc. XVI), e de xilogravuras de Rudolph Speckle (séc. XVI). Conforme afirma Paolo Rossi, no prefácio da obra, Leonhart Fucks registra que tomara todos os cuidados necessários para que todas as plantas fossem representadas com as raízes, caules, folhas, flores, sementes e frutos. Sua preocupação era com a exatidão e não com a estética, e por isso cuidou para que não se representassem as espécies conforme eram na realidade (Rossi, 2001, p. 97).

Leonhart Fuchs organizou a descrição de mais de quinhentas espécies por ordem alfabética, procurando organizar em cada capítulo um gênero e suas subdivisões. Preocupou-se com o registrar das diferentes partes e seus nomes, destacando as diversas morfologias e propriedades das plantas. Porém, seus estudos restringem-se a descrições gerais das flores, seus odores, cores e folhas sem delimitar as espécies por seus órgãos de reprodução ou de frutificação. Se por um lado, os trabalhos pouco acrescentavam em informações de base científica, por outro conseguiram sistematizar e catalogar as espécies, contribuindo para o avanço de outros estudos.

Valerius Cordus de Oberhessen (1515-1544), demonstrando um ávido interesse por plantas, realizou viagens que resultaram na elaboração da Annotationes in Pedacii Dioscoridis de Matéria medica livros $V$, publicada após sua morte em 1561. A obra reunia a descrição de uma série de plantas analisadas sob o ponto de vista do uso farmacêutico, com descrições precisas e minuciosas, confirmando o desejo de catalogação das espécies. 0 trabalho de Valeris Cordus de Oberhessen foi continuado pelo suíço Konrad Gesner (1516-1565) que empreendeu um amplo trabalho sobre espécies da flora, apresentando a estrutura das plantas.

Konrad Gesner demonstrou desde cedo ser um aluno estudioso dedicando-se ao conhecimento do grego e do hebraico, e publicou a Bibliotheca universali sive catalogus omnium scriptorum locupletissimus in tribus linguis Latina, Graeca et Hebraica, uma bibliografia que registrava os livros impressos em latim, grego e hebraico. Em 1537, foi professor de grego na Academia de Lausanne, onde estudou Medicina. Konrad Gesner escreveu a obra Opera botânica (Trabalhos botânicos) que continha mais de 1.300 gravuras, que seria completada após a sua morte. A obra classificava as plantas em florescentes e não-florescentes e identificava cada uma pelo modo pelo

\footnotetext{
${ }^{6}$ Dioscoride, nas suas obras De materia medica e Peri hules latrikes (Sobre as plantas medicinais) registra a diversidade do mundo natural a partir das viagens que realizara. Na obra De materia medica o autor registra vegetais, animais e minerais, fornecendo os nomes mais comuns e a propriedade de cada espécie. Ele opta por fazer a observação direta das espécies, realizando registros detalhados como podem ser identificados nos desenhos que realizou.
} 
qual a seiva era suprida. Os estudos de Konrad Gesner não ficaram restritos à botânica, pois também se dedicou à zoologia e elaborou a obra Historia animalium (História dos animais - em cinco volumes publicados entre 1551-1587), com mais de 3.500 páginas e que seria finalizada após a sua morte (Ronan, 1987, vol. III, p. 22). Contudo, ele não fez uso da anatomia comparada. Sua classificação dos animais foi feita em ordem alfabética, sendo cada animal descrito em capítulos amplos, subdividido em seções. Nestas foram feitos os registros do nome do animal em várias línguas, o habitat onde eram encontrados, comportamentos, formas de criação e procriação, bem como o possível uso para alimentação ou para a medicina. Agrupou os animais em: quadrúpedes (vivíparos e ovíparos) pássaros, peixes, crustáceos, insetos e anfíbios (Rossi, 2001, p. 348).

Naqueles idos, as pesquisas no âmbito da fauna tinham como referência os trabalhos de Pierre Belon e Guillaume Rondelet. 0 francês Pierre Belon (1517-1564) recebeu formação como farmacêutico e provavelmente estudou botânica com Valerius Cordus. Por meio de uma rede de relações obteve licença para praticar Medicina, e ocupou um lugar na corte do rei Carlos IX (1550-1574). Realizou viagens pela Europa e Oriente Próximo, visitando a Grécia, a Turquia e o Egito, das quais resultaram anotações sobre o mundo natural e a elaboração de três obras. No texto La nature et diversité des poissons (A história natural de estranhos peixes marítimos - 1551), estudava cetáceos e peixes, revelando o trabalho de Belon na identificação das glândulas mamárias dos cetáceos que ele classificou como mamíferos. Outra obra foi Sobre a vida aquática (1553), que tratava das espécies que habitam rios e mares. Na obra L'histoire de la nature des oyseaux avec leurs descriptions et naïfs protraicts retirez du naturel (A história e natureza dos pássaros - 1555), Pierre Belon faz descrições detalhadas sobre a anatomia das aves, fruto de suas dissecações, comparando os resultados com o esqueleto humano. Seus estudos também se dirigiam à botânica, para redigir um tratado sobre as coníferas, conhecido como De arboribus coniferis, resiniferis, aliisque, nonnullis sempiterna fronde virentibus [...]

Guillaume Rondelet (1507-1566), por sua vez, estudou inicialmente humanidades na Universidade de Paris, passando em seguida a cursar medicina. Conquistou reconhecimento como professor de anatomia e Medicina em Montpellier, mas o trabalho que o tornou conhecido foi o estudo intitulado De piscibus marinis (Livro dos peixes marinhos), escrito em latim e publicado em Lyon, entre os anos de 1554-1555. Em 1558, a obra foi traduzida com o título L'Histoire entiere des poissons, composee premierement en Latin par Maistre Guillaume Rondelet [...] (A história completa dos peixes). 0 texto apresentava o sistema digestivo, respiratório e reprodutivo de animais aquáticos. As reflexões avançavam na medida em que fazia estudos comparativos entre o ouvido do golfinho, do porco e do ser humano. Num tom claramente enciclopédico, Rondelet analisou e dissecou várias espécies, chamando a atenção para a importância desta prática no processo de construção do conhecimento.

No final do século XVI e início do XVII ficava evidente que os antigos sistemas de classificação não eram suficientes para explicar as novas descobertas. Era necessária a criação de novas bases que pudessem dar inteligibilidade ao conhecimento mais técnico de cada espécie. Em diferentes partes da Europa surgiam estudos que reuniam informações e resultados de pesquisas que apontavam para uma nova etapa do pensamento racional.

Andrea Cesalpino (1519-1563) estudou na Universidade de Pisa, onde adquiriu conhecimentos sobre filosofia, medicina e botânica. Conhecedor dos textos de Aristóteles, fez uma das primeiras tentativas para classificar flores e frutos, com base em princípios aristotélicos (matéria e forma). Em De plantis libri XVI (1583) descreve aproximadamente 1.500 plantas apresentado-as como seres vegetativos que, conforme o pensador grego, eram organismos simples. Rigoroso em suas observações, não aceita critérios como "gosto", utilização farmacêutica para a classificação das plantas. Para ele, o sistema de compreensão da natureza deveria levar em conta a morfologia e a fisiologia dos vegetais.

Outro estudioso importante foi o bolonhês Ulisse Aldrovandi (1522-1605). De espírito irrequieto seguiu para Roma, onde manteve contato com Guillaume Rondelet aproximando-se da História Natural, e estudou sobre vegetais analisando os órgãos reprodutores. Em 1561, passou a lecionar na Universidade de Bologna temas ligados à História Natural, e formou o primeiro jardim botânico italiano, um herbário com aproximadamente 7.000 espécies. Empreendeu estudos de 
embriologia e dedicou parte da sua vida à pesquisa de pássaros e insetos; classificou mais de 1.500 variedades de cada um. Como homem do seu tempo, demonstrou interesse em relação aos quadrúpedes, árvores e minerais e fez também ponderações fantásticas. Em sua obra Histoire naturelle (1599-1603) dedicou atenção aos pássaros, registrou espécies da África, Ásia e América, cometendo algumas impressões. Tal situação não impediu que fossem desprezadas suas descrições sobre hábitos alimentares, técnicas de captura e utilidade dos mesmos para a medicina. Seu trabalho referia aspectos que os pesquisadores que o antecederam não mencionavam.

Os estudos mineralógicos no século XVI também revelam o interesse dos pesquisadores sobre a metalurgia e a mineralogia. As obras Descrição dos métodos de mineração e processamento de minério de chumbo (1574), de Lazarus Ercker (1528-1594) e De re Metallica (Metalurgia - 1555), de Georgius Agrícola (1494-1555) constituem dois estudos que primam pela descrição dos métodos mais adequados para analisar os metais preciosos, afastando-se das práticas dos alquimistas (Rohou, 2002, p. 134).

No âmbito da medicina Georg Bauer, que fora aluno da Universidade de Leipzig, organizou a publicação dos trabalhos de Hipócrates e Galeno. Observador da natureza fez estudos de sementes e de seus usos para fins médicos. Seu trabalho consistiu no exame de fósseis, estudos de geologia, sempre destacando que as suas observações eram fruto de uma experiência pessoal. A ideia de que o conhecimento não vinha apenas dos livros, como defendiam os escolásticos, ganhou adeptos que admitiam que o homem só adquiria conhecimento pela observação do objeto. Paolo Rossi sentenciou:

Captar o que é essencial e menosprezar o supérfluo. Mas onde procurar o que é essencial? e como detectar o supérfluo? Os ensaístas da Antigüidade e da Renascença, nas suas obras, davam amplo espaço às interpretações alegóricas, aos mitos, às lendas relativas a um determinado animal e a certa planta, ou à sua comestibilidade, aos possíveis usos, e às representações poéticas e literárias (Rossi, 2001, p. 348).

Mediante ao acima exposto podemos destacar que no final do século XVI era evidente que as viagens de descobertas haviam promovido a circulação cultural e bens materiais que levaram os indivíduos a indagarem sobre a ordem do saber vigente. A Europa conhecia-se e avaliava-se em função da emergência das novas culturas, que paulatinamente iam sendo identificadas, impulsionadas e expandidas pelo surgimento e desenvolvimento da imprensa. Como observou Luís Filipe Barreto, "os descobrimentos foram uma imensa explosão dos limites da terra e do mar, uma nova e maior extensão dos horizontes e modalidades de comunicação intercivilizacional" (Barreto, 1987, p. 10). 0 reconhecimento de novas culturas deu ensejo à ampliação dos horizontes econômicos e a um desenvolvimento mercantil mais acentuado, promoveu alterações nos padrões comportamentais como um todo.

Essa alteração ou reordenação da estrutura mental europeia de incorporação do novo/desconhecido processou-se de maneira morosa no seio do corpo social. 0 novo adquiriu forma por meio dos conhecimentos informativos dos viajantes e também por meio dos estudos de diversos homens que desejaram rever os parâmetros estabelecidos. Como observa Paolo Rossi:

O mundo terrestre é o mundo da alteração e da mutação, do nascimento e da morte, da geração e da corrupção. O Céu, ao contrário, é inalterável e perene, os seus movimentos são regulares, nele nada nasce e nada se corrompe, mas tudo é imutável e eterno. As estrelas, os planetas (o Sol é um deles) que se movem ao redor da Terra não são formados pelos mesmos elementos que compõem os corpos do mundo sublunar, mas por um quinto elemento divino: o éter ou quinta essência, que é sólido, cristalino, imponderável, transparente e não sujeito a alterações. As esferas celestes são feitas da mesma matéria. Sobre o equador destas esferas em rotação (como "nós em uma tábua de madeira") são fixados o Sol, a Lua e os outros planetas (Rossi, 2001, p. 36).

As transformações materiais e as conquistas dos homens resultaram novas observações e indagações sobre as formas de ser, sentir, estar e ver a natureza. Gianni Micheli ao analisar o naturalismo renascentista, observou com propriedade: 
O nascimento da ciência moderna, que trouxe consigo uma renovação radical dos princípios básicos e dos métodos de investigação da ciência tradicional, pressupunha a ruptura global do quadro geral de referências da investigação científica; a consequente aspiração a uma nova ordem alternativa do conhecimento da natureza parte, portanto, de um terreno em que se reproduz a antinomia entre investigação racional abstracta e investigação empírica das origens (Einaudi, 1990, p. 21).

A preocupação com o método advém do fato de o homem não aceitar a autoridade do conhecimento do período anterior. Era preciso reexaminar o mundo e criar fundamentos para as ideias, independente da tradição. 0 método implicava a regra e na ordenação. 0 pensamento humano deveria valer-se da razão para estabelecer o ordenamento, discutir a ocupação sequencial de cada elemento, identificar vínculos e estabelecer comparações. Esta renovação radical dos princípios básicos e dos métodos de investigação foi designada por estudiosos como revolução científica ou, como afirmou Thomas Kuhn, como um momento de quebra de paradigmas. 0 que podemos observar é que uma nova ordem para o conhecimento da natureza se desenvolvia levando à investigação racional e empírica. A odisséia humana na busca dos enigmas da natureza caminhava para uma nova fase.

Nesse contexto de reordenação de saberes e quebra de paradigmas tem participação importante o mundo natural da América portuguesa. Uma natureza incógnita que se apresenta aos olhos dos europeus, que pouco a pouco procura descobrir os segredos das novas terras. 0 avanço pelo interior do território brasileiro e sua ocupação possibilitariam o aprofundamento do conhecimento sobre os habitantes da terra e sua fauna e flora. Novos saberes surgiram e suscitaram questionamentos que estimularam novas investigações e novos olhares. Pesquisas e explorações que estão longe de findar tendo em vista a grandiosidade de um mundo social e natural que favorece a produção de novos saberes.

\section{Referências}

Azzi, R. (1983). Descobrimentos e renascimento: formas de ser e pensar nos séculos XV e XVI. Lisboa: Casa da Moeda.

Barreto, L. F. (1986). Os caminhos do saber no Renascimento Português. Lisboa: INCM.

Barreto, L. F. (1987). Os Descobrimentos e a Ordem do Saber - Uma análise sociocultural. Lisboa: Gradiva.

Braga, M., Guerra, A., \& Reis, J. C. (2005). Breve História da Ciência Moderna. Rio de Janeiro: Zahar.

Bruno, G. (1984). Acerca do infinito, do universo e do mundo. Lisboa: Fundação Calouste Gulbenkian.

Carvalho, J. de (1947). Estudos sobre a cultura portuguesa do século XVI (Vol. I). Coimbra: Univ. de Coimbra.

Crafton, A. (1999). Cardano's cosmos - the worlds and works of a Renaissance astrologer. Cambridge.

Dias, J. S. da S. (1988). Os descobrimentos e a problemática cultural do século XVI. Lisboa: Presença.

Einaudi (1990). Natureza - Esotérico/Exotérico. Lisboa: Imprensa Nacional da Casa da Moeda, vol. 18.

Freitas, R. S. (2005). "A metodologia como carro-chefe da história da ciência". In B. G. Figueiredo \&, M. L. L. Condé (Orgs.). Ciência, História e Teoria. Belo Horizonte: Argumentum.

Giucci, G. (1992). Viajantes do maravilhoso - o novo mundo. São Paulo: Companhia das Letras.

Hale, J. R. (1983). A Europa durante o Renascimento (1480-1520). (A. Sabler, Trad.). Lisboa: Presença.

Heinberg, R. (1991). Memórias e visões do paraíso. Rio de Janeiro: Campus.

Heller, A. (1982). O Homem do Renascimento. (C. Jardim \& E. Nogueira, Trad.). Lisboa: Presença. 
Hutter, L. M. (2004). Navegação nos séculos XVII e XVIII - rumo: Brasil. São Paulo: Edusp.

Khun, T. (2003). A estrutura das revoluções científicas (7a. ed.). São Paulo: Perspectiva.

Khun, T. (1990). A revolução copernicana: a astronomia planetária no desenvolvimento do pensamento Ocidental. Lisboa: Edições 70.

Khun, T. (2006). O caminho desde a estrutura. São Paulo: Editora UNESP.

Marías, J. (2004). História da Filosofia. São Paulo: Marins Fontes.

Martin, H. (1996). Mentalités médiévales, XIème - XVème siècle. Paris: Presses Universitaires de France.

More, T. (1985). A Utopia. (Coleção Pensadores). São Paulo: Nova Cultural.

O’Gorman, E. (1992). A invenção da América. São Paulo: Editora da Unesp.

Rohou, J. (2002). Le XVIIe siecle, une révolution de la condition humaine. Paris: Seuil.

Ronan, C. A. (1987). História Ilustrada da Ciência (4 vols.). Rio de Janeiro: Jorge Zahar Editor.

Rossi, P. (2001). O nascimento da ciência moderna na Europa. São Paulo: Edusc.

Rotterdam, E. (1988). Elogio da loucura. (P. M. Oliveira, Trad. e Notas). São Paulo: Nova Cultural. 